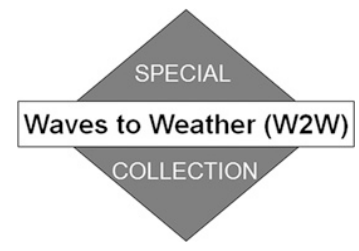

\title{
The Impact of Dropsonde and Extra Radiosonde Observations during NAWDEX in Autumn 2016
}

\author{
MATTHIAS SCHINDLER \\ Meteorologisches Institut, Ludwig-Maximilians-Universität, Munich, Germany \\ MARTIN WEISSMANN \\ Hans-Ertel Centre for Weather Research, Deutscher Wetterdienst, Munich, Germany, and Institut für Meteorologie \\ und Geophysik, Universität Wien, Vienna, Austria \\ ANDREAS SCHÄFLER \\ Institut für Physik der Atmosphäre, Deutsches Zentrum für Luft- und Raumfahrt, Oberpfaffenhofen, Germany \\ GABOR RADNOTI \\ European Centre for Medium-Range Weather Forecasts, Reading, United Kingdom
}

(Manuscript received 2 May 2019, in final form 18 November 2019)

\begin{abstract}
Dropsonde observations from three research aircraft in the North Atlantic region, as well as several hundred additionally launched radiosondes over Canada and Europe, were collected during the international North Atlantic Waveguide and Downstream Impact Experiment (NAWDEX) in autumn 2016. In addition, over 1000 dropsondes were deployed during NOAA's Sensing Hazards with Operational Unmanned Technology (SHOUT) and Reconnaissance missions in the west Atlantic basin, supplementing the conventional observing network for several intensive observation periods. This unique dataset was assimilated within the framework of cycled data denial experiments for a 1-month period performed with the global model of the ECMWF. Results show a slightly reduced mean forecast error $(1 \%-3 \%)$ over the northern Atlantic and Europe by assimilating these additional observations, with the most prominent error reductions being linked to Tropical Storm Karl, Cyclones Matthew and Nicole, and their subsequent interaction with the midlatitude waveguide. The evaluation of Forecast Sensitivity to Observation Impact (FSOI) indicates that the largest impact is due to dropsondes near tropical storms and cyclones, followed by dropsondes over the northern Atlantic and additional Canadian radiosondes. Additional radiosondes over Europe showed a comparatively small beneficial impact.
\end{abstract}

\section{Introduction}

Over the past few decades, the quality of mediumrange weather forecasts steadily improved, which is attributable to numerous factors that paved the way for the revolution numerical weather prediction (NWP) has experienced (Bauer et al. 2015). The introduction of more sophisticated data assimilation algorithms to optimally harness observational information and the extensive use of satellite data to curtail initial condition errors are some of the most important innovations in the

Corresponding author: Matthias Schindler, m.schindler@lmu.de process (Simmons and Hollingsworth 2002; Bauer et al. 2015). While satellite data assimilation is indispensable due to its temporal and spatial data coverage, providing the majority of observations that are assimilated every day, in situ observations of diabatically active regions associated with tropical cyclones (TCs) and midlatitudinal frontal systems are quite limited to a few observations provided by buoys and a scarce observation network of radiosondes and adaptively deployed dropsondes. However, these cloudy regions typically correspond to areas of substantial error growth, which corroborates the need for additional observations to confine forecast errors (McNally 2002). 
The impact of adaptive observations that augment the comparatively data-sparse oceanic baseline observing network has been an active and partly controversial research field over the past two decades. Around the turn of the century, several studies indicated that targeted dropsonde observations could reduce the forecast error of NWP models in regional verification areas on the order of $10 \%-20 \%$ (Montani et al. 1999; Langland 1999; Szunyogh et al. 2000, 2002). This motivated several field campaigns in the framework of the WMO THORPEX program. Subsequent studies assimilating additional dropsonde observations in midlatitude regions, however, merely found a small to neutral impact when results were averaged over longer periods and larger regions (Langland 2005; Rabier et al. 2008; Majumdar et al. 2011; Hamill et al. 2013; Majumdar 2016). Nevertheless, a significant beneficial impact of additional observations was demonstrated for typhoon track prediction (Aberson 2003; Chou et al. 2011; Harnisch and Weissmann 2010; Weissmann et al. 2011) and the subsequent midlatitudinal development following the extratropical transition (ET) of TCs (Weissmann et al. 2011, 2012). The impact of adaptive observations strongly depends on the underlying data assimilation scheme, the numerical model, the specification of the baseline observing network and the utilized targeting method (Hamill et al. 2013; Majumdar 2016). On the one hand, the amount of assimilated satellite observations has increased drastically over the past few decades and the skill of NWP models has generally increased, which leaves less room for improvement through the assimilation of additional observations. On the other hand, data assimilation systems have improved through, for example, the use of flow-dependent covariances and better treatment of observation and representation errors which should lead to an increased impact of observations.

In contrast to earlier field experiments that employed objective targeting methods, the North Atlantic Waveguide and Downstream Impact Experiment (NAWDEX; Schäfler et al. 2018) placed a stronger focus on an improved understanding of the underlying physical and dynamical processes. Utilizing a multitude of in situ and remote sensing instruments, a comprehensive dataset was collected in autumn 2016, with four research aircraft being coordinated to sample various weather systems that exhibit increased diabatic activity. During the campaign, 289 dropsondes (191 assimilated) were deployed over the northern Atlantic basin to yield information on vertical profiles of water vapor, temperature, and wind, complemented by additional radiosonde launches from 40 stations located over Canada and Europe. In addition, the NOAA (National Oceanic and
Atmospheric Association) affiliated SHOUT (Sensing Hazards with Operational Unmanned Technology) and Reconnaissance missions were conducted to sample TCs and their immediate vicinity to improve model guidance of storm track and intensity forecasts in the western Atlantic basin (Dunion et al. 2018). This wealth of additional observations supplemented the conventional observing network during 13 intensive observation periods (IOPs) that included High Impact Weather (HIW) events of low forecast skill as well as forecast busts. Autumn 2016 featured an increased frequency of extratropical cyclones and their associated warm conveyor belts (WCBs), a prominent blocking regime and six tropical storms, among which were the two major Hurricanes Matthew and Nicole, as well as Tropical Storm (TS) Karl. Even though Karl did not attain hurricane strength, the observed cyclone provided an unprecedented observational dataset, as Karl was sampled from its early TS stages up to its ET and a subsequent heavy precipitation event affecting Norway (Schäfler et al. 2018).

The influence of the collected observational data on forecast performance during the entire campaign period is investigated via cycled data denial experiments with the global model of the European Centre for MediumRange Weather Forecasts (ECMWF) and assessing the Forecast Sensitivity to Observation Impact (FSOI) method. This enables an assessment of the accumulated observation impact as well as the relative importance of different observation types and observed parameters.

The study is organized as follows: section 2 provides a brief overview of the data assimilation and modeling system and the performed data denial experiments. Results from the denial experiments and the evaluation of the observation impact based on FSOI are presented in section 3. Finally, the conclusions of the study are summarized in section 4 .

\section{Methodology}

\section{a. Additional observations}

During NAWDEX, four research aircraft were equipped with in situ and remote sensing instruments to observe atmospheric conditions with a focus on profile observations of wind, temperature and humidity at a sufficiently high temporal and spatial resolution to investigate horizontal and vertical gradients related to a number of meteorological phenomena of interest (Schäfler et al. 2018). Instead of relying on objective targeting methods to estimate regions of increased forecast sensitivity, NAWDEX aimed at observing diabatic processes that are expected to be sources of uncertainty in current NWP models. Following subjective 


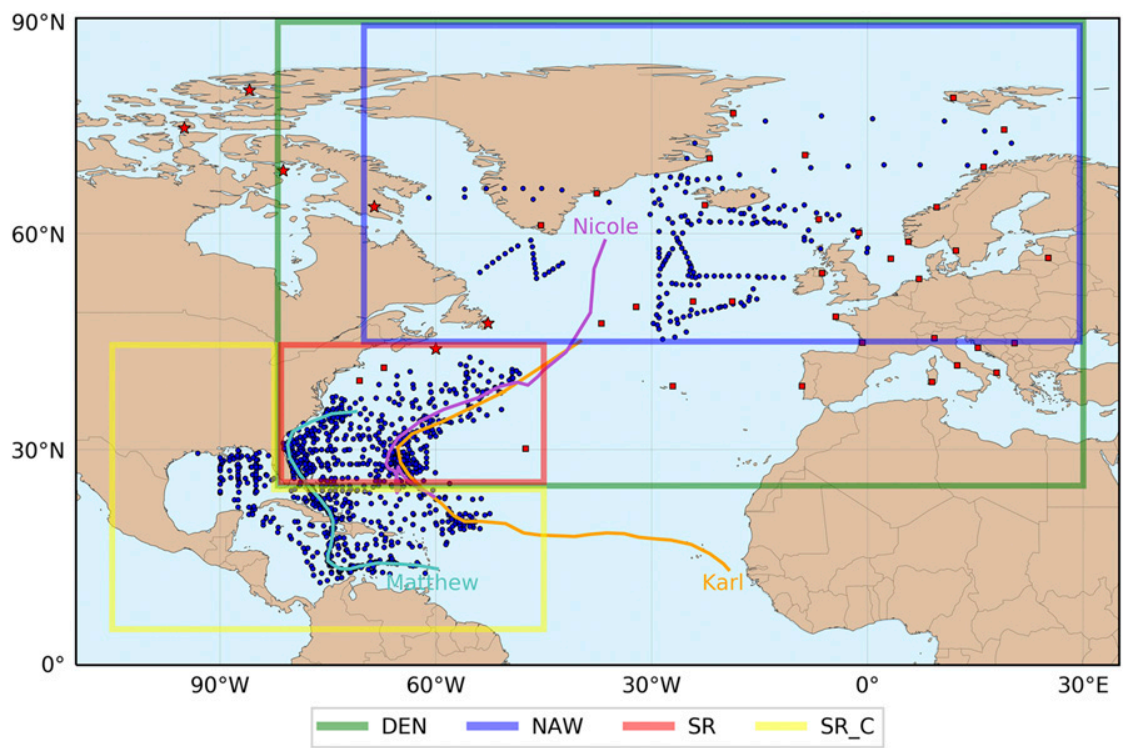

FIG. 1. Dropsondes (blue markers) and additional radiosonde observations (red markers) during NAWDEX and SHOUT in autumn 2016, along with best tracks of Tropical Storm Karl and Hurricanes Matthew and Nicole. Canadian radiosondes are depicted by red stars. Colored boxes mark specific areas of interest: complete denial region (DEN; $25^{\circ}-90^{\circ} \mathrm{N}, 82^{\circ} \mathrm{W}-30^{\circ} \mathrm{E}$ ), midlatitude denial subregion (NAW; $45^{\circ}-90^{\circ} \mathrm{N}, 70^{\circ}-30^{\circ} \mathrm{W}$ ), SHOUT and Reconnaissance associated denial subregion (SR; $25^{\circ}-45^{\circ} \mathrm{N}, 82^{\circ}-45^{\circ} \mathrm{W}$ ), and SHOUT and Reconnaissance associated region outside of DEN area (SR_C).

synoptic guidance, 191 dropsondes were deployed over the northern and western Atlantic basin, focusing on observations of midlatitude cyclones and WCBs (cf. Fig. 1). At the same time, over 1000 dropsondes were deployed in the western Atlantic region and the Gulf of Mexico during SHOUT and Reconnaissance missions to provide additional observations of TCs, their environmental conditions and their subsequent ET (Dunion et al. 2018; Wick et al. 2018).

Dropsondes of NAWDEX were released either from high altitudes between 11.5 and $14.2 \mathrm{~km}$ in radarcontrolled airspace or at roughly $8 \mathrm{~km}$ beneath the main North Atlantic air traffic. During SHOUT the unmanned aircraft system Global Hawk was used, which is capable of conducting high-altitude and long-endurance flight missions. These aircraft systems can operate at flight levels between 16 and $20 \mathrm{~km}$, while reconnaissance flights of NOAA and the Air Force Weather Reconnaissance Squadron typically operate at a lower ceiling of $8.5 \mathrm{~km}$, also depending on the payload and sampled region (e.g., at lower levels for penetrating TCs). More detailed information on the NAWDEX and SHOUT aircraft, their instrumentation and the deployment of dropsondes is provided in Schäfler et al. (2018) and Dunion et al. (2018), respectively.

Moreover, 589 radiosondes (471 assimilated) were additionally launched from 40 stations over Canada, the
North Atlantic, and Europe, including several launches from commercial ships (cf. Table 1). 253 of these radiosondes were launched upon request to extend the observational coverage during NAWDEX IOPs, accomplished by the cooperation of meteorological agencies as part of the European Meteorological Services Network (EUMETNET). In addition, Canadian radiosondes were launched from six stations in eastern Canada for the entire NAWDEX period with two additional launches per day. Both dropsonde and radiosonde observations yield information on temperature, humidity, and wind that was assimilated within the framework of cycled data denial observing system experiments (OSEs).

\section{b. Model setup and experiments}

The numerical experiments were performed with the global model of the ECMWF using the model version

TABLE 1. Total number of dropsondes for subregions as specified in Fig. 1 and total number of additional radiosondes launched over Canada (CA), Europe (EUR), and from ships (SHIP).

\begin{tabular}{lcc}
\hline \hline \multicolumn{1}{c}{ Status } & Dropsondes & Radiosondes \\
\hline Denied & NAW (191) & CAN (316) \\
Denied & SR (533) & EUR (148) \\
Denied & SHIP (7) \\
Not denied & SR_C (541) & \\
All denied & 724 & 471 \\
\hline
\end{tabular}


that became operational shortly after NAWDEX in December 2016 (cycle 43r1). This model configuration utilizes a horizontal resolution of about $9 \mathrm{~km}$ on a cubic octahedral grid with spectral truncation 1279 (TCo1279; Malardel et al. 2016) and 137 sigma levels in the vertical, with a model top of $0.01 \mathrm{hPa}$. The data denial experiments were cycled over the whole campaign period (i.e., from 17 September to 18 October 2016) using the four-dimensional variational (4D-Var) data assimilation scheme of the ECMWF Integrated Forecasting System (IFS) (Rabier et al. 2000). The incremental 4D-Var formulation makes use of a single outer loop at full resolution (TCo1279) to update the nonlinear model forecast states and three inner loops at a gradually increasing resolution for the subsequent cost function minimization on a reduced Gaussian grid with linear truncation (TL255/TL319/TL399). As in the operational configuration, forecasts are initialized from an analysis that combines background information from an earlier 12 -h assimilation window (2100-0900 or 09002100 UTC) with the observations during a subsequent 6-h assimilation window (0900-1500 or 2100-0300 UTC). This implies that the 12-h assimilation window always overlaps with the preceding 6-h assimilation window.

A denial experiment (DNL) was set up to exclude observations from 724 dropsondes in a prescribed North Atlantic region $\left(25^{\circ}-90^{\circ} \mathrm{N}, 82^{\circ} \mathrm{W}-30^{\circ} \mathrm{E}\right)$ as well as from 471 additionally launched radiosondes that were collected during NAWDEX and associated field campaigns (cf. Table 1). The denial region comprises observations north of $25^{\circ} \mathrm{N}$ as midlatitude impact is the primary focus of this study. The control experiment (CTL) assimilates all available observations including all dropsondes as well as additional radiosondes. Both CTL and DNL consider all available satellite and conventional observations that are operationally assimilated at ECMWF, such that the only difference in the assimilated dataset is presented by the observational subset that was collected during NAWDEX and SHOUT. The conducted experiments also include a 25 -member ensemble of data assimilation (EDA) with a lower resolution of $18 \mathrm{~km}$ (TCo639) that was computed separately for CTL and DNL to achieve independent estimates of the background error covariance matrix and the analysis error (Isaksen et al. 2010; Bonavita et al. 2012).

\section{c. Forecast sensitivity to observation impact (FSOI)}

The FSOI serves as a diagnostic tool to further assess the impact of observations. This diagnostic has the advantage that it provides an estimate of the impact of individual observations in addition to the accumulated impact that can be assessed with the cycled data denial experiments (Cardinali 2009; Gelaro and Zhu 2009).
Constrained by the validity of the underlying tangent linear assumption, the adjoint of the NWP model is used to propagate the sensitivity of a scalar function $J$ of the forecast state backward in time. The resultant sensitivity gradient with respect to the initial state is then mapped from analysis to observation space by applying the adjoint of the data assimilation system. This provides the sensitivity of the final forecast state with respect to the observations, such that the FSOI can be expressed as

$$
\mathrm{FSOI}=\left\langle\left(\mathbf{y}-\mathbf{H} \mathbf{x}_{b}\right), \frac{\partial J}{\partial \mathbf{y}}\right\rangle,
$$

where $\mathbf{y}, \mathbf{H}$, and $\mathbf{x}_{b}$ denote the observation vector, the linearized observation operator, and the background state vector, respectively (Baker and Daley 2000; Langland and Baker 2004; Cardinali 2009; Amerault et al. 2013). As a result, this adjoint-based procedure allows an estimation of the contribution of collected observations to a potential degradation or improvement of the quality of the short-range 24-h forecast error. While moist processes are included in the computation of the adjoint, a global dry energy norm up to a height of $0.01 \mathrm{hPa}$ is utilized as an objective metric in the sensitivity gradient computation. This combination has proven to provide reasonable gradients and associated observation impacts (Janisková and Cardinali 2016).

FSOI is evaluated for several regions of interest that allow a differentiation of observation impact between individual components of the additional observations during NADWEX and SHOUT (cf. Fig. 1). Therefore, the data denial region (DEN) is subdivided into SHOUT and Reconnaissance observations of TCs and their ET (SR) as well as into midlatitudinal observations of cyclones associated with the NAWDEX campaign (NAW). Further dropsonde deployments in the southern Atlantic region and the Gulf of Mexico (SR_C) were not denied in DNL but evaluated in terms of FSOI. As the first half of the 12-h assimilation window assimilates observations that were already used in the preceding 6-h window, we only evaluate observations from 1500 to 0300 UTC for forecasts initialized at 0000 UTC and observations from 0300 to 1500 UTC for the forecasts initialized at 1200 UTC.

\section{d. Modified dropsonde quality control}

In the current ECMWF system, dropsonde and radiosonde observations are treated in the same manner, in that dropsonde observations are assimilated at a fixed point in space and time to provide an instantaneous vertical profile. A large potential error source is therefore associated with the fact that the horizontal dropsonde drift is not taken into account. This is 
partially accounted for by a new adaptive dropsonde quality control introduced by Bonavita et al. (2017). For dropsonde observations that exhibit large departures from the model first guess, the new quality control accounts for errors of representativity as well as errors in the forward model by increasing the observation error of these dropsonde measurements. In that way, detrimental observations are not discarded completely but are merely assigned a smaller weight before entering the data assimilation algorithm. Bonavita et al. (2017) showed that this procedure increases the beneficial impact of dropsondes, in particular for dropsondes near TCs that often exhibit substantial observation background departures. This modified dropsonde quality control was not included in the operational model version during NAWDEX, and we will therefore show a comparison of dropsonde FSOI for the operational model run and our control experiment CTL.

\section{Results}

\section{a. Data denial experiments}

\section{1) MEAN DIFFERENCES}

Figure 2 illustrates the normalized difference in absolute forecast error of $500-\mathrm{hPa}$ geopotential as a function of lead time and longitude, verified against the operational ECMWF analysis. The resulting differences are averaged temporally over the whole campaign period and spatially over a latitudinal band extending from $25^{\circ}$ to $90^{\circ} \mathrm{N}$. While there are a few periods with a smaller forecast error of DNL, as well as several regions and forecast lead times with negligible differences between the performed experiments, an overall reduction in the forecast error of CTL up to $3 \%$ predominates forecast lead times up to $72 \mathrm{~h}$. This demonstrates an overall beneficial impact of the additional dropsonde and radiosonde observations assimilated in experiment CTL compared to DNL without additional observations.

In Fig. 3 the reduction in the mean forecast error is quantified in terms of the root-mean-square error (RMSE) of 500-hPa geopotential for different verification regions. A small improvement (i.e., a reduction in the forecast error of CTL) is evident up to a forecast lead time of $96 \mathrm{~h}$ for all regions of interest. The additional observations reduced the short-range forecast error by about $1 \%-2.5 \%$ over DEN and a prescribed European verification region (Figs. 3a,b), with a consistent improvement throughout all forecast lead times. Moreover, improvements of about $3 \%$ relative to DNL become evident for the southwestern Atlantic SR verification region that covers three recurving TCs (Karl, Matthew,

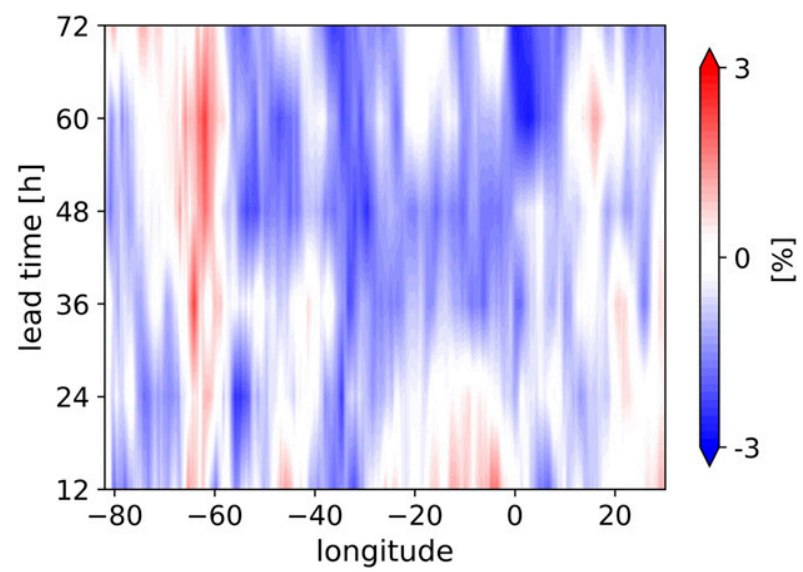

FIG. 2. Difference in absolute forecast error (CTL-DNL) in 500-hPa geopotential, normalized by the mean error of the corresponding lead time and averaged for a latitudinal band between $25^{\circ}$ and $90^{\circ} \mathrm{N}$.

and Nicole) as well as their ET (Fig. 3d). Similar improvements are found for the North Atlantic, though error reductions start to decrease after day 2 (Fig. 3c). This beneficial signal is consistently found for several atmospheric variables such as relative humidity, wind and temperature and for different pressure levels (not shown). Overall, the mean error reduction is of a similar magnitude as the mean reduction found in data denial experiments for the THORPEX Pacific Asian Regional Campaign (T-PARC) 2008 conducted with the ECMWF system at that time (Weissmann et al. 2011).

While SHOUT and Reconnaissance dropsondes mainly focused on observations of TCs, the evaluation of TC track errors did not reveal a clear improvement (not shown). However, it should be noted that only dropsondes north of $25^{\circ}$ latitude (i.e., observations shortly before, during, and after the recurvature of Karl and Matthew) were denied as TC track prediction was not the primary focus of this study. This leads to a fairly small sample size for the evaluation.

\section{2) TEMPORAL EVOLUtion}

While the average forecast error shows an error reduction of up to a few percent, there are forecast periods with significantly larger reductions of up to $30 \%$. Figure 4 presents a time series of the $500-\mathrm{hPa}$ geopotential RMSE, verified over DEN at a forecast lead time of $48 \mathrm{~h}$. Even though the performed experiments exhibit only minor differences for most initialization times, there are three periods that correspond to central NAWDEX IOPs for which the 2-day forecasts of CTL manifest significantly smaller errors. The most prominent differences between DNL and CTL appear to be associated with Tropical Storm Karl (IOP4) 

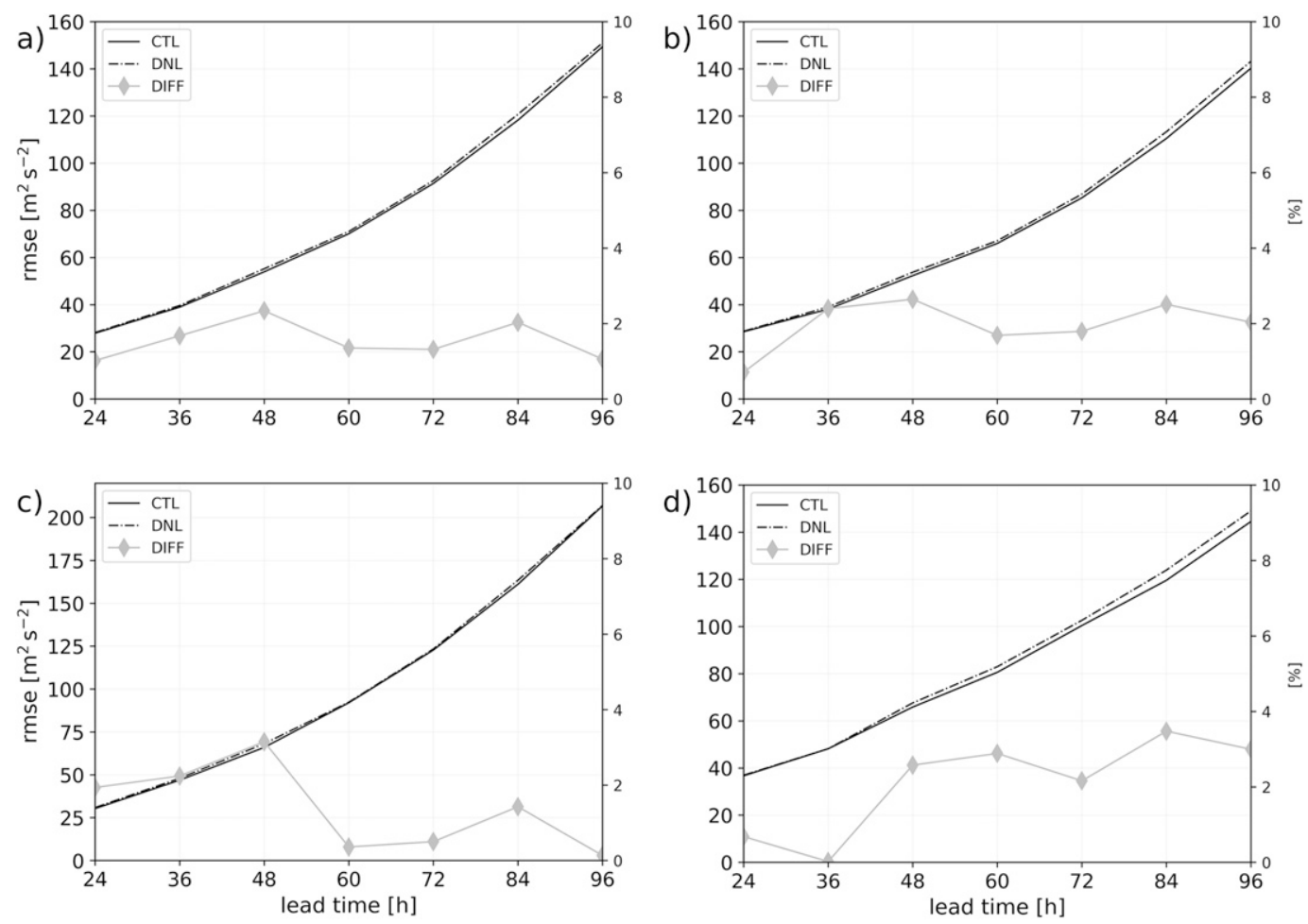

FIG. 3. RMSE (black lines) of 500-hPa geopotential for CTL (solid) and DNL (dashed) and difference (DNL CTL) relative to DNL in RMSE (gray lines), averaged over the whole campaign period and verified against the operational ECMWF analysis for the (a) DEN, (b) European $\left(30^{\circ}-75^{\circ} \mathrm{N}, 20^{\circ} \mathrm{W}-40^{\circ} \mathrm{E}\right)$, (c) North Atlantic $\left(45^{\circ}-\right.$ $\left.75^{\circ} \mathrm{N}, 70^{\circ}-10^{\circ} \mathrm{W}\right)$, and (d) SR verification region.

transitioning into the midlatitudes and merging with an extratropical cyclone over the North Atlantic (2425 September), Hurricane Matthew transitioning into the midlatitudes and the downstream development of a cutoff low named Sanchez (IOP 10; 8-9 October), as well as an unobserved event over the central North Atlantic toward the end of the campaign period that is linked to the interaction of Hurricane Nicole with the

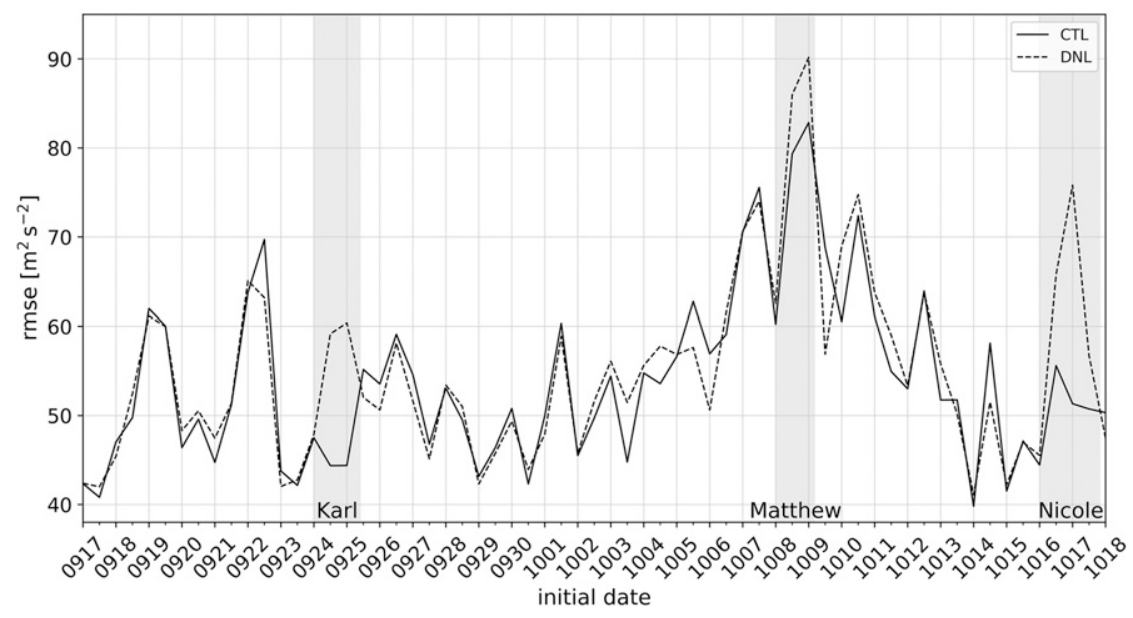

FIG. 4. Time series of RMSE of the 2-day forecast of 500-hPa geopotential for CTL (solid) and DNL (dashed), averaged over the whole campaign period and verified against the operational ECMWF analysis over DEN. Time periods that cover the most prominent differences between CTL and DNL are highlighted by gray shading. 

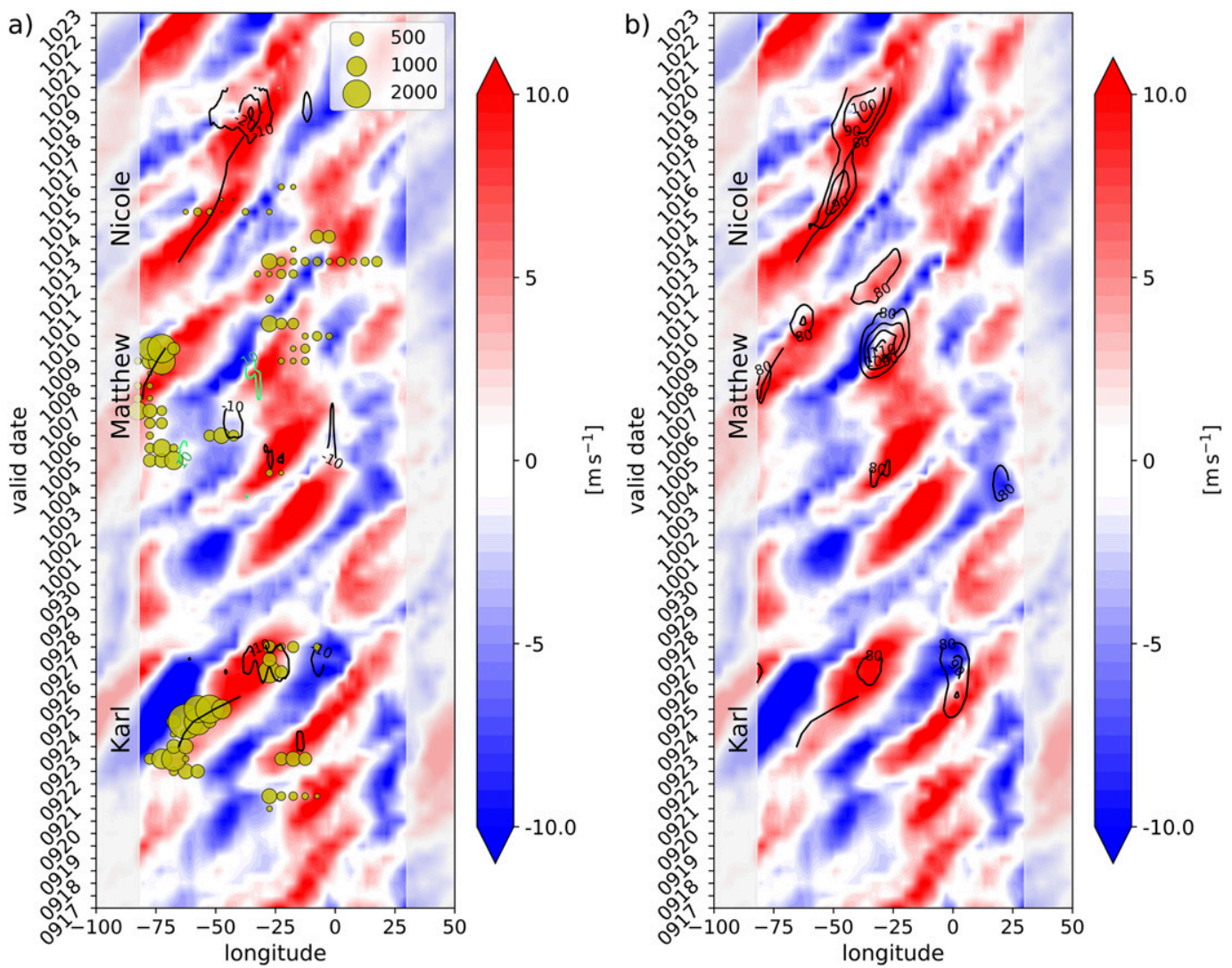

FIG. 5. Hovmoeller diagram of the IFS analysis of meridional wind at $300 \mathrm{hPa}$ in red/blue colors, zonally accumulated number of dropsonde observations per analysis cycle for a band of $5^{\circ}$ longitude, with the marker size increasing with the total number of observations (yellow markers), best tracks for Tropical Storm Karl, Hurricanes Matthew and Nicole, and (a) difference in absolute forecast error (CTL - DNL) of 500-hPa geopotential shown by black/green contour lines for negative/positive differences and (b) operational EPS spread, averaged for a latitudinal band between $30^{\circ}$ and $80^{\circ} \mathrm{N}$ (black contour lines).

midlatitude waveguide (16-18 October). There are also individual days that show a reduced 2-day forecast error for DNL, implying a deterioration of the forecast performance when additional observations are assimilated. In contrast to the three dominant cases that show a persistent reduction in forecast error for CTL, signals that indicate a deterioration are much smaller and in addition comparatively limited in their temporal extent with maximum values of around $12 \%$ relative to DNL. The most prominent deterioration exhibits values of $20 \%$, but is rather transient as it merely appears in one cycle on 10 October.

To relate signals of forecast improvement to additional observations that sampled specific weather events during NAWDEX, Fig. 5a combines a Hovmoeller-type diagram of the operational meridional wind analysis at $300 \mathrm{hPa}$ and the difference in the absolute forecast error of 500-hPa geopotential between CTL and DNL at a forecast lead time of $48 \mathrm{~h}$. In addition, best tracks for TS Karl and Hurricanes Matthew and Nicole, as well as the zonally accumulated number of dropsonde observations for each analysis cycle are displayed. Overall, the collected observations lead to an improvement of the 2-day forecast quality, while only a few periods exhibit increased forecast errors that are in addition comparatively limited in their spatial extent. Consistent with Fig. 4, the reduction in the forecast error of CTL is again tied to the three specific periods mentioned above.

The widespread reduction in forecast error of CTL starting around 26 September can be directly linked to the evolution of Karl and additional observations farther upstream, sampling the storm from its early stages up to the development that followed its ET and merging with an extratropical cyclone [see also Fig. 7 in Schäfler et al. (2018)]. Coinciding with the spatiotemporal extent of these large error differences, a region of increased forecast uncertainty is indicated by the operational Ensemble Prediction System (EPS) spread for 48-h forecasts (Fig. 5b). Therefore, it can be hypothesized that the collected observations reduced some of the 
inherent uncertainty associated with the dynamically sensitive processes related to the cyclone's ET and the subsequent midlatitude development, which still poses a major challenge to numerical weather prediction (Jones et al. 2003; Evans et al. 2017).

Though not showing such a pronounced difference in the 2-day forecast errors (below contouring), the development around 11 October is of special interest as the largest overall forecast errors for both experiments arise during this period (cf. Fig. 4) and the operational ensemble likewise exhibited particularly large spread around this date (Fig. 5b). Moreover, this development is linked to a HIW event associated with heavy precipitation in southwestern Europe. While there were many dropsonde observations along the track of Hurricane Matthew and downstream over the eastern Atlantic in the period from 3 October to 10 October, the differences between the experiments are less distinct and more difficult to relate to specific meteorological features. Figure 5a shows three areas with reduced forecast errors of CTL in the period from 5 October to 7 October. These may partly be influenced by upstream observations near Matthew, but may also result from the influence of Canadian radiosondes and the cycling of the experiments for nearly three weeks prior to this period. Furthermore, the regions of reduced forecast error in this period do not coincide with the regions of increased ensemble spread.

Toward the end of the campaign period (1820 October), another region of widespread error reduction developed downstream of Hurricane Nicole merging with a large extratropical storm southeast of Greenland (Fig. 5a). As there were no dropsonde observations in the vicinity of Nicole, the apparent error reduction may originate from the impact of upstream Canadian radiosondes or the cycled impact of observations collected in the previous weeks. As for IOP Karl, the reduction in the 2-day forecast error is largest directly downstream of the tropical storm, where the forecast uncertainty likewise exhibits a localized maximum (Fig. 5b). Corresponding to the difference in forecast errors, there is also an elongated along-track region of ensemble spread tied to forecast uncertainties concerning the position and intensity of Nicole.

\section{b. Case study}

The foregoing characterization of forecast errors over the campaign period showed that the most prominent forecast error reductions were linked to periods of tropical storm events (cf. Figs. 4 and 5). In the following, we demonstrate analysis differences of CTL and DNL during TS Karl's ET and its interaction with the midlatitude waveguide and investigate the spatial and temporal distribution of forecast errors at different lead times.

Figures $6 \mathrm{a}$ and $6 \mathrm{~b}$ show differences in the analysis of 500-hPa geopotential between CTL and DNL as well as dropsonde and best track storm positions. Dropsonde observations of SHOUT and Reconnaissance extensively sampled TS Karl transitioning into the midlatitudes for the analysis cycles of 1200 UTC 24 September and 0000 UTC 25 September, when the storm was reintensifying and began merging with a low pressure system south of Greenland. The collected observations lead to pronounced negative differences surrounding the storm center that indicate the development of a deeper cyclone in CTL (Fig. 6a), which is further substantiated by an investigation of the mean sea level pressure field (not shown). Positive geopotential differences are located farther downstream in the outflow region of the recurving TS, especially on the anticyclonically sheared southern flank of the jet stream. This suggests the onset of a stronger ridge building process in CTL (Fig. 6b). The amplification of the downstream ridge is presumably associated with a more pronounced deepening of TS Karl during its
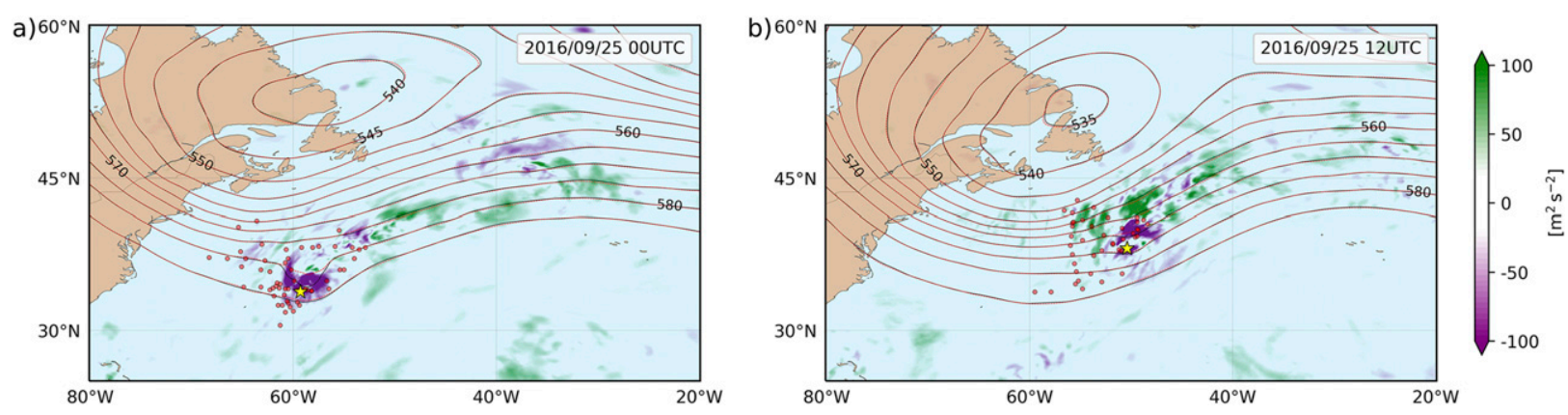

FIG. 6. Difference in analysis of 500-hPa geopotential (CTL - DNL) in green/purple colors and corresponding contour lines of the 500-hPa geopotential height analysis in decameters for experiments CTL (black) and DNL (red) for (a) 0000 UTC 25 Sep and (b) 1200 UTC 25 Sep. Locations of deployed dropsondes are displayed by red markers, while the best track storm position of TS Karl is presented by a yellow star marker. 
reintensification phase and accordingly a stronger outflow that is capable of penetrating farther to the north and thus producing a more intense ridge (Grams et al. 2013; Grams and Archambault 2016; Keller et al. 2019).

Differences in the absolute forecast error between CTL and DNL for forecasts initiated at 1200 UTC 25 September are displayed by Fig. 7. In agreement with the investigation of analysis differences, a slightly stronger ridge building is initiated downstream of TS Karl in CTL (cf. contour lines in Fig. 7a) after $12 \mathrm{~h}$, which corresponds to a widespread and dominant reduction in forecast error (Fig. 7a). This downstream signal weakens beyond a lead time of $36 \mathrm{~h}$ (not shown) when the ridge intensification ceases in a rather diffluent flow over northern Europe. At a lead time of $24 \mathrm{~h}$ (Fig. 7b), forecast error differences reveal a dipole structure at the leading edge of the frontal system that merged with TS Karl, associated with a stronger cyclone and a westward shift of the storm center in CTL (cf. contour lines in Fig. 7b). The dipole structure propagates toward the British Isles with increasing lead time, following the track of the low pressure system that is again merging with a preexisting extratropical low north of the British Isles until $48 \mathrm{~h}$ (Fig. 7c). Negative differences in the region where the CTL forecast provides a weaker cyclone farther northwest indicate a reduction in forecast error, whereas a weaker trough in the CTL experiment farther downstream shows an increase in forecast error.
However, these positive differences quickly diminished and at a forecast lead time of $72 \mathrm{~h}$ (Fig. 7d), the dipole structure transformed into a distinct region of forecast error reduction over northern Europe.

\section{c. Forecast Sensitivity to Observation Impact (FSOI)}

Figure 8 shows a time series of the impact of dropsonde observations estimated by FSOI for the denial subregions NAW and SR (cf. Fig. 1), as well as the total number of observations that contribute to the impact. Observations in the NAW region (Fig. 8a) were deployed during several IOPs that focused on diabatically active regions (Schäfler et al. 2018). Except for a few events that exhibit a small detrimental impact, the NAWDEX observations overall indicate a beneficial impact and contribute to a reduction of the short-range forecast error. Dropsonde observations with the largest beneficial FSOI contribution are connected to IOP 3 (23 September) research flights that sampled the WCB ascent and outflow of cyclone Vladiana (Oertel et al. 2019; Schäfler et al. 2019, submitted to Mon. Wea. Rev.) with particularly large impacts tied to observations associated with the flight leg focusing on the WCB outflow region (cf. Fig. 9a). Moreover, dropsondes deployed during coordinated flights for IOP 12 (13 October) observing an extended anticyclone north of Iceland (cf. Fig. 9b) likewise exhibit substantial contributions to a reduction in the short-range forecast error.
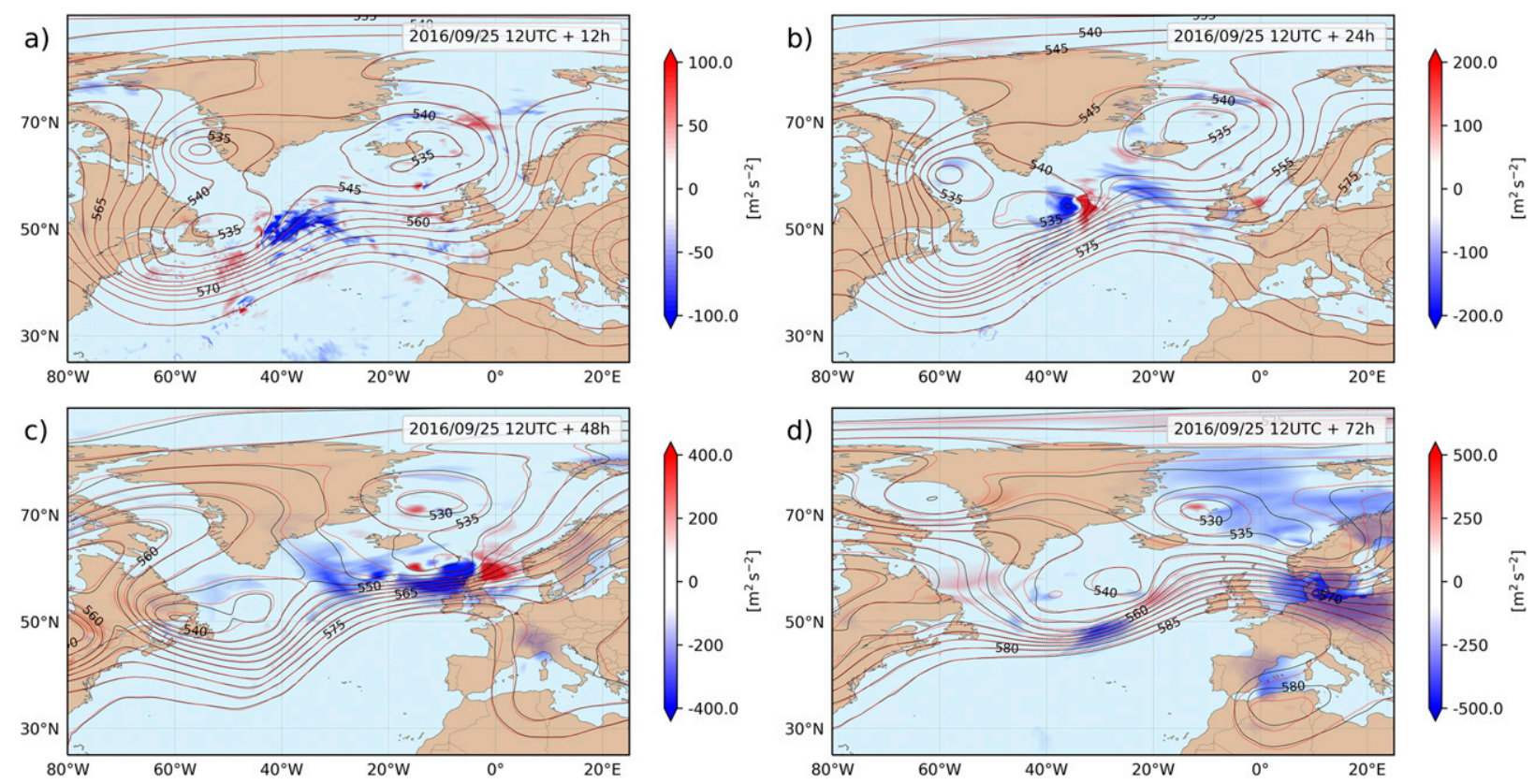

FIG. 7. Difference in absolute forecast error of 500-hPa geopotential (CTL - DNL) in red/blue colors and corresponding contour lines of the 500-hPa geopotential height forecast in decameters for experiments CTL (black) and DNL (red) for forecast lead times of (a) 12, (b) 24, (c) 48, and (d) $72 \mathrm{~h}$, initiated from 1200 UTC 25 Sep. 

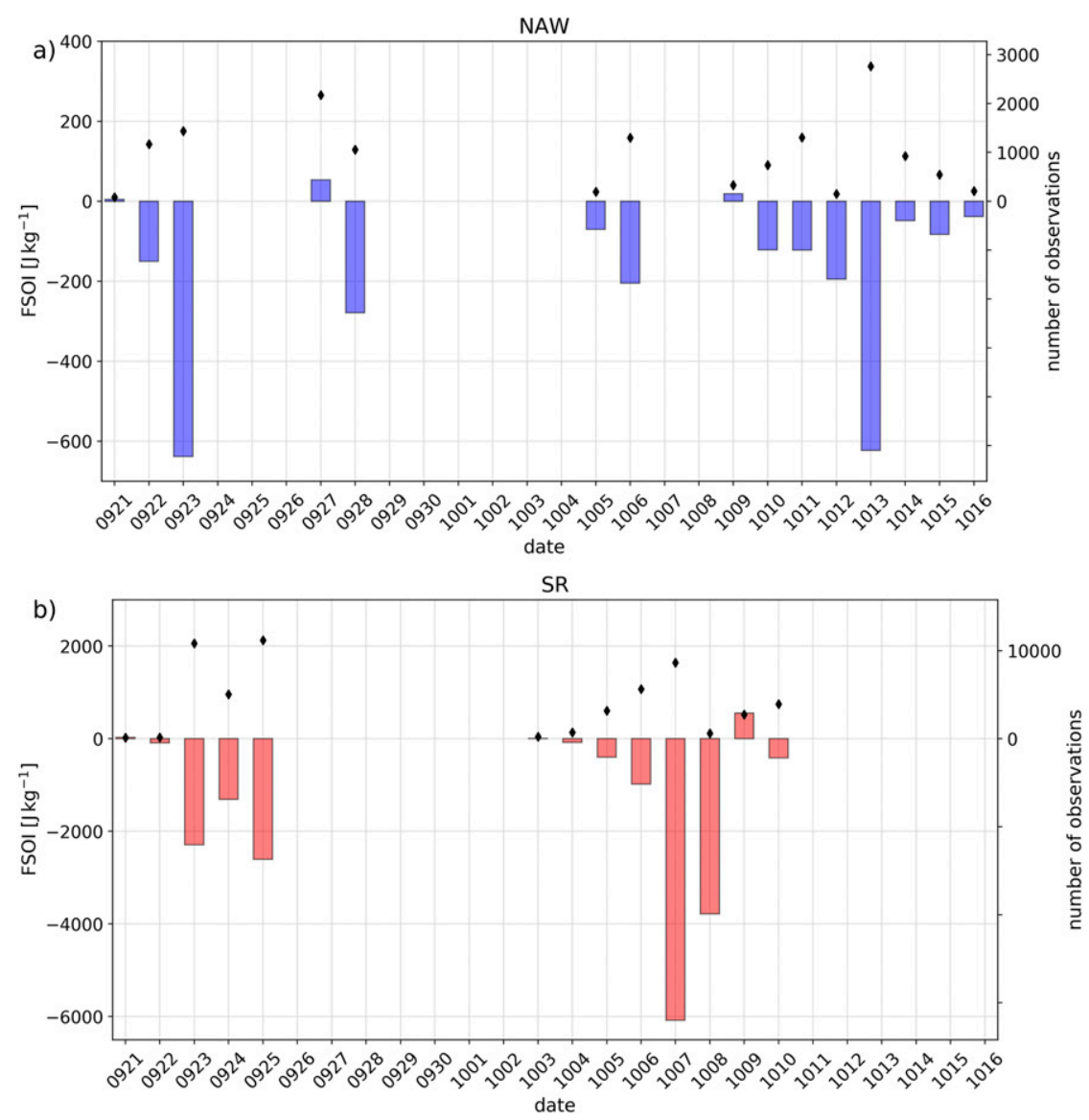

FIG. 8. Time series of total FSOI (bars) and number of observations (diamond markers) for denial subregions (a) NAW and (b) SR.

A considerably larger number of dropsondes was deployed during the SHOUT and Reconnaissance missions that focused on tropical storms and their subsequent ET (Fig. 8b). This led to a considerably higher impact (note the different scaling of the axis for the number of observations and impact compared to the results for the NAW region in Fig. 8). The largest beneficial impact in the SR subregion is associated with observations of TS Karl (23 September and 25 September; cf. Figs. 9c,d) and Hurricane Matthew (7 October and 8 October; cf. Figs. 9e,f) around the time of their recurvature and subsequent interaction with the midlatitude waveguide. The larger impact of observations for Matthew may be related to the larger intensity of Matthew compared to Karl. Temporally, the largest FSOI roughly coincides with the first two episodes that exhibit large forecast error differences (cf. Fig. 4). However, the causal relationship between observations near Matthew and midlatitude forecast differences downstream is not completely clear and the forecast differences may also result from cycling effects and Canadian radiosondes as mentioned before. Furthermore, it should be noted that FSOI only provides an estimate of observation impact that has been validated globally in a statistical sense, but not for individual cases in a TC environment.

Figures 10a and 10b illustrate the FSOI per observation for dropsonde and radiosonde observations, averaged over the whole campaign period for experiment CTL. When focusing on the impact of the deployed dropsondes in the denial region, which is composed of the midlatitudinal NAWDEX observations (NAW) and SHOUT and Reconnaissance related observations of TCs (SR), it becomes apparent that the gathered dropsonde observations are overall contributing to a reduction of the short-range forecast error. The largest beneficial impact per observation is associated with the sum of the meridional and horizontal wind components and is considerably larger for dropsondes in the vicinity of TCs. The large impact of wind is presumably attributable to the fact that TCs are large potential error sources and conventional wind observations over the ocean are still quite limited. Furthermore, the lack of geostrophic balance makes wind observations more 

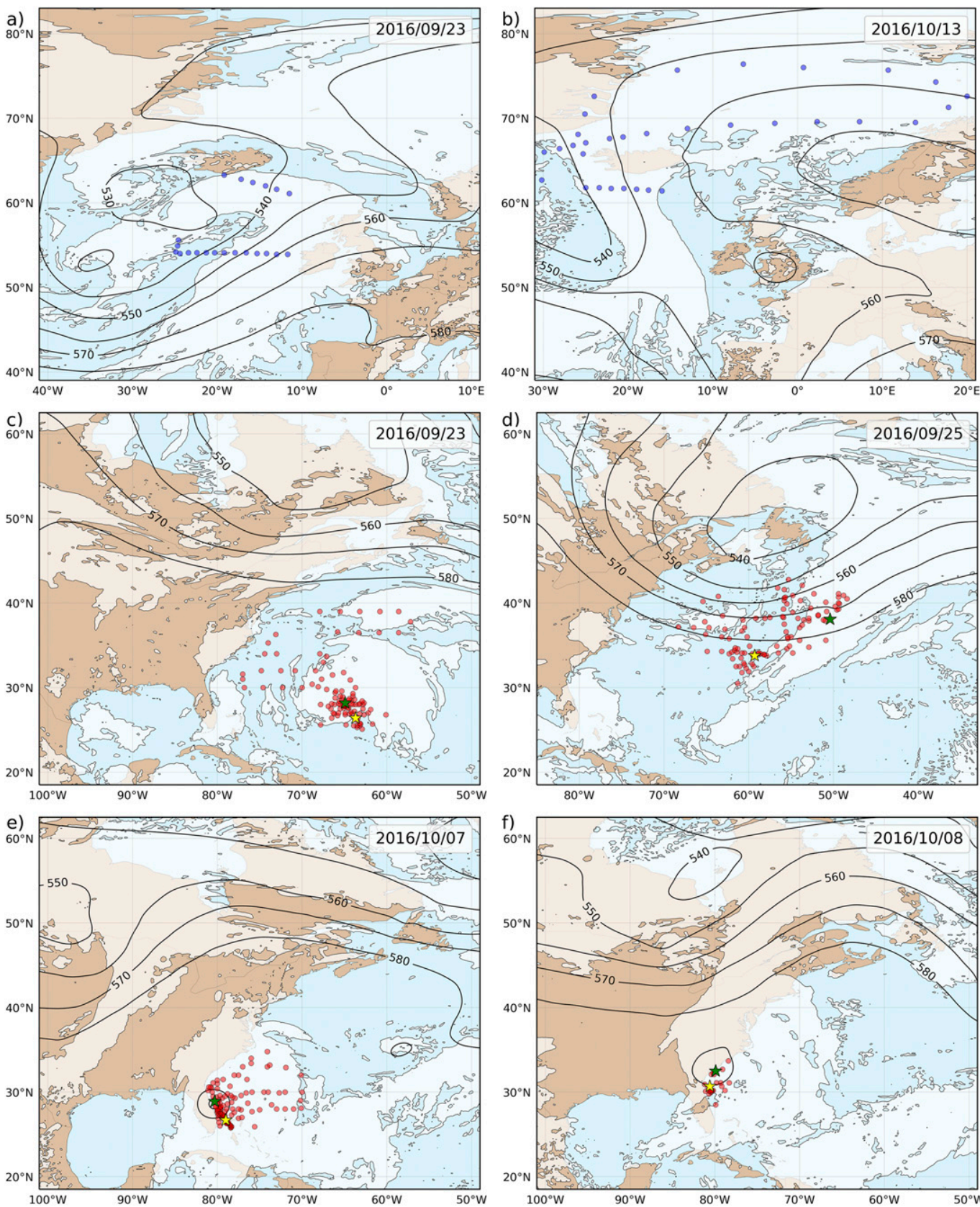

FIG. 9. Dropsonde deployments for high impact flights of NAWDEX and SHOUT (cf. Fig. 8) (blue, red markers), with contour lines of the operational 500-hPa geopotential height analysis in decameters and filled contours of total cloud cover at 1200 UTC (a) $23 \mathrm{Sep}$, (b) 10 Oct, (c) $23 \mathrm{Sep}$, (d) $25 \mathrm{Sep}$, (e) 7 Oct, and (f) 8 Oct. For SHOUT research flights best track positions of Tropical Storm Karl and Hurricane Matthew are displayed by yellow (0000 UTC) and green (1200 UTC) star markers.

important in tropical regions compared to the midlatitudes (Baker et al. 2014). For the midlatitudinal NAWDEX observations, the accumulated impact of wind is smaller in magnitude and comparable to that of temperature, while the smallest impact in the denial region is related to specific humidity. This is likely due to the fact that moisture is a highly variable field and observational information is not spread out via any underlying balance assumption as is the case for wind and temperature. Moreover, moisture predominantly acts as a passive tracer most of the time and only becomes dynamically important when phase changes occur. 

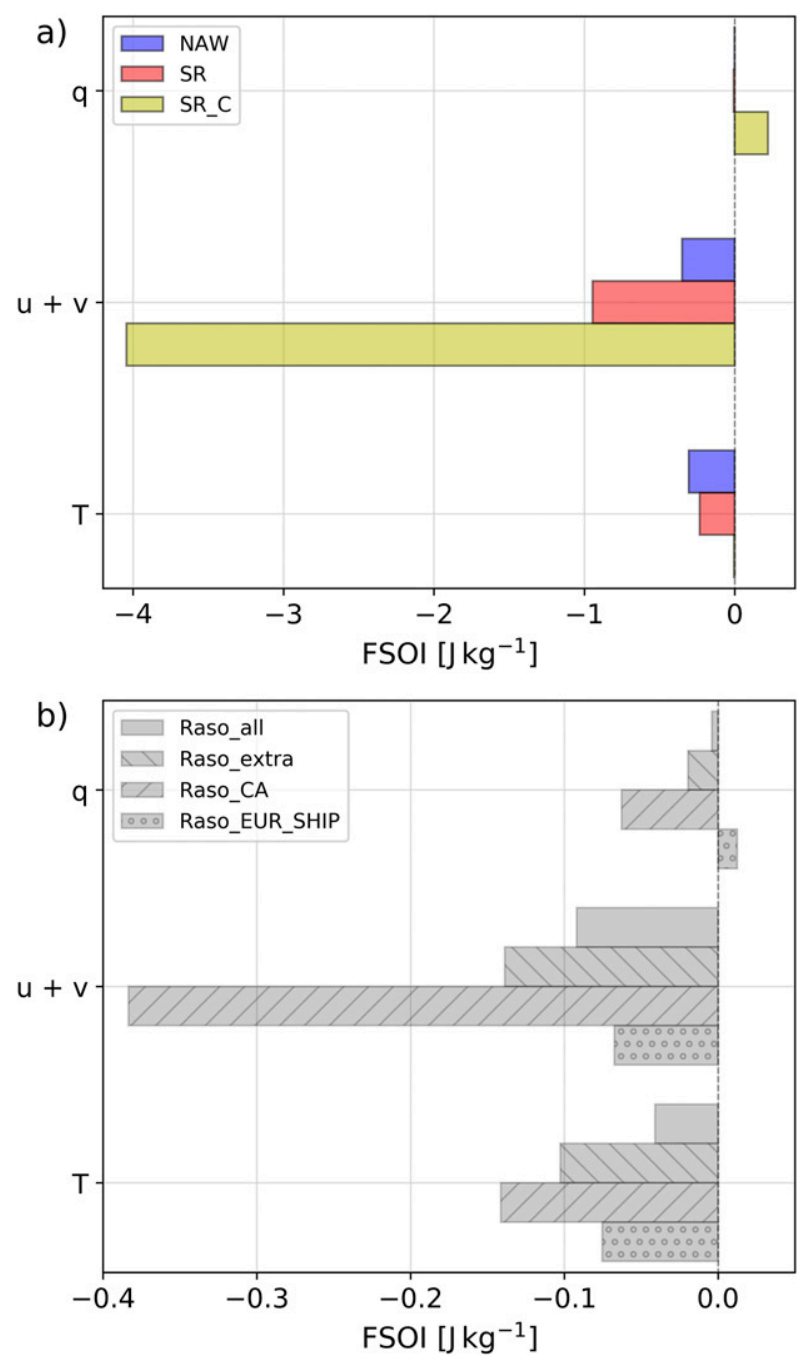

FIG. 10. FSOI per observation for specific humidity, sum of the horizontal wind components, and temperature for (a) dropsondes and (b) radiosondes for experiment CTL, averaged over the campaign period. For dropsondes FSOI is presented for the subregions NAW, SR, and SR_C (cf. Fig. 1), while the impact of radiosondes is represented by all assimilated radiosonde observations (Raso_all), only additional radiosonde observations (Raso_extra), additionally launched Canadian Radiosondes (Raso_CA), and additionally launched European and ship-based radiosondes (Raso_EUR_SHIP).

As for the dropsonde observations, there is a beneficial impact associated with observations by extra radiosondes (Fig. 10b), with a particularly large impact per observation by the additionally launched Canadian radiosondes that were deployed in comparatively datasparse regions at high latitudes and upstream of evolving weather systems (Peevey et al. 2018). The impact is again largest for wind and smallest for specific humidity. Compared to the mean impact of all global radiosondes, the impact of additional Canadian radiosondes was about four times higher. European and ship-based radiosondes exhibit a clearly smaller impact per observation than extra Canadian radiosondes and their impact is overall comparable to the mean impact of all global radiosondes.

To investigate the effect of the modified dropsonde quality control (Bonavita et al. 2017) that was operationally introduced at ECMWF shortly after NAWDEX, a comparison of the dropsonde FSOI for the operational model run with the old quality control and CTL with the new quality control is shown in Fig. 11. The new adaptive quality control reveals a significant influence on the impact of dropsonde wind observations. Whereas the old static quality control included a simple blacklisting of observations that exhibit large observation background departures, hence potentially eliminating valuable observational information, more observations are able to enter the data assimilation system with the modified adaptive quality control. By increasing the error of doubtful observations, a smaller weight is assigned to dropsonde observations that manifest substantial observation background departures, while fully exploiting the available observational information. With the new quality control, the impact of wind observations is 5-7 times higher than with the old quality control for dropsondes in the two regions that include TCs (SR and SR_C). This further emphasizes the benefit of the new quality control that was also shown by Bonavita et al. (2017). However, CTL also employs a newer model version (cycle 43r1) than the operational model (cycle 41r2) at that time and is therefore not directly comparable. As for data assimilation, changes included in the new model version incorporate an increase in the spectral resolution for the computation of EDA background error estimates from TL159 to TL399 and the introduction of a wavelet noise filter to damp sampling noise (see ECMWF (2019) for further details concerning 43r1 model changes). These model changes lead to an increase in background error variance, thus effectively increasing the weight assigned to observations, which might have also contributed to the enhanced impact.

Dropsonde wind observations in the extratropical NAW region exhibit a slightly reduced impact. It should be noted that the adaptive QC was designed to mitigate issues that arise with observations of active TC regions, therefore potentially being suboptimal for observations of extratropical systems and giving less weight to extratropical observations with large differences to the model first guess. However, the difference in impact is small and may therefore also be related to the different model versions used for CTL and the operational run.

Figure 12a shows the relative impact of dropsondes and radiosondes in different regions as a fraction of the 


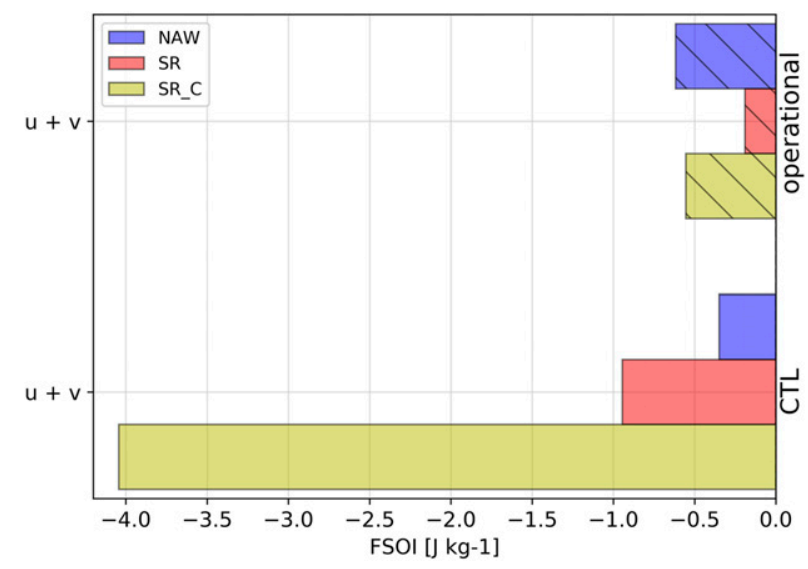

FIG. 11. FSOI per observation for the sum of the horizontal wind components for dropsondes assimilated in the operational model run (dashed) and CTL.

impact of all additional observations. The largest contribution to the total impact is provided by SR dropsonde observations in the southwestern Atlantic basin, which is in accordance with preceding results that show a significant impact of observations in active TC regions. This further emphasizes the value of observations near TCs that was also found by Weissmann et al. (2011). Around $20 \%$ of the total impact is associated with Canadian radiosondes, while North Atlantic dropsonde deployments account for $8 \%$ of the impact. Taking into account the higher number of observations in the SR region, the differences in impact are reduced (Figs. 12b,c). Nevertheless, SR dropsondes still exhibit the largest impact per observation, which is about twice as large as the impact of extratropical NAW dropsonde observations. In comparison, the impact of additionally launched Canadian radiosondes is nearly as high as that of dropsondes in the NAW region. NAWDEX dropsonde and Canadian radiosonde observations exhibit an impact that is 4-5 times larger than that of additional European radiosondes or the average impact of global radiosondes shown in Fig. 10.

\section{Conclusions}

The impact of dropsonde and extra radiosonde observations that were collected during the trans-Atlantic field campaign NAWDEX and the concurrent NOAA missions SHOUT and Reconnaissance is evaluated in the framework of cycled data denial experiments. A control experiment (CTL) includes observations from dropsondes and additionally launched radiosondes that complement the baseline observing network, while a denial experiment (DNL) was set up to exclude these additional observations.

The experiments revealed a mean forecast error reduction between $1 \%$ and $3 \%$ for several verification regions, demonstrating an overall beneficial influence of the additional observational information assimilated in CTL. Overall, the mean reduction in forecast error was of a similar magnitude as found for the T-PARC 2008 field campaign that also included a combination of observations of tropical cyclones, their extratropical transition and extratropical systems (Weissmann et al. 2011). Hamill et al. (2013), in contrast, only found a very small impact of midlatitude targeted dropsonde observations during the Winter Storm Reconnaissance Program.

Even though the mean forecast error reduction is limited to a few percent, an investigation of the 2-day forecast RMSE time series for the 500-hPa geopotential
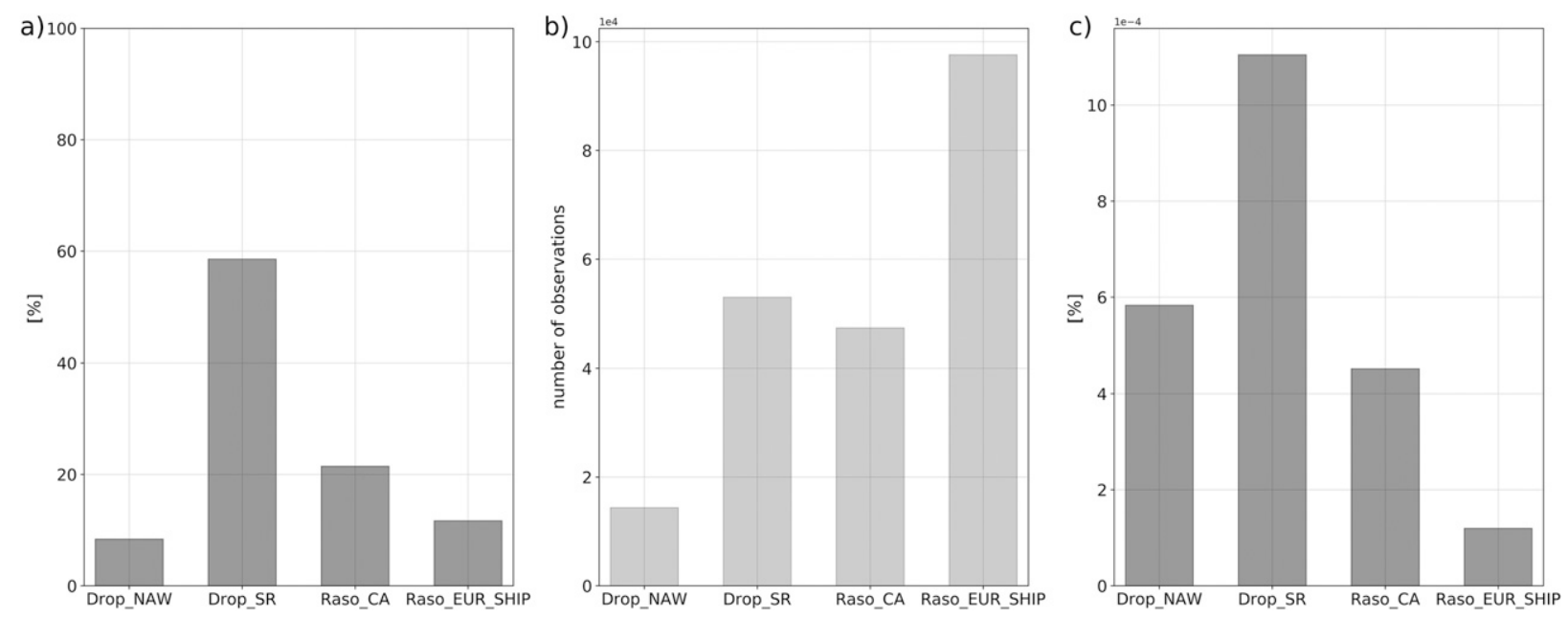

FIG. 12. (a) Relative total impact, (b) number of observations, and (c) impact per observation for NAW (Drop_NAW) and SR (Drop_SR) dropsondes, as well as for additionally launched Canadian (Raso_CA) and European (Raso_EUR_SHIP) radiosondes. 
shows several cases with increased differences of up to $30 \%$. In particular, the experiments indicate that episodes with tropical storms transitioning into the midlatitudes are particularly sensitive to additional observations. The most prominent forecast error reduction is associated with TS Karl and Hurricane Nicole interacting with the midlatitude flow. While dropsonde observations that sampled Karl and its environment are clearly linked to a pronounced reduction in forecast error directly downstream of the storm, there were no dropsonde observations sampling Nicole. Therefore, the apparent reduction in forecast error toward the end of the campaign period may be linked to the cycled impact of the collected observations during the preceding weeks and the impact of upstream Canadian radiosondes. For both Karl and Nicole, regions of forecast error reduction coincide with regions of increased EPS spread, indicating that the collected observations effectively reduced some of the inherent uncertainty tied to the storms' recurvature and their subsequent interaction with the midlatitude waveguide. While Nicole exhibited a distinct forecast error reduction in the absence of direct observations, Hurricane Matthew was sampled extensively. Despite a midlatitude forecast error reduction downstream of Matthew, it is difficult to relate forecast differences to the observations near Matthew.

A brief case study focusing on TS Karl's interaction with the waveguide and its transition into the midlatitudes linked the extensive sampling of TS Karl to prominent differences in the analysis between CTL and DNL, suggesting the development of a deeper storm and an amplified ridge building in experiment CTL. In agreement with these analysis differences, prominent signals of forecast error reduction downstream of TS Karl were linked to the initiation of a stronger ridge building process in forecasts of CTL. Moreover, forecast error differences also indicated a dipole structure emanating from the merging of Karl with a preexisting low south of Greenland. With increasing lead time, differences indicating an increase in forecast error gradually diminished, while signals of forecast error reductions persisted and propagated toward northern Europe.

In contrast to studies with other models that indicate a beneficial impact of dropsonde observations for the track prediction of Karl and Matthew (Christophersen et al. 2018; Kren et al. 2018; Wick et al. 2018), we found no clear improvements concerning TC track, intensity and wind speed forecasts. However, only dropsondes north of $25^{\circ}$ latitude were denied in our experiment leading to a fairly small sample size for the evaluation.

Consistent with the denial experiments, an investigation of the FSOI time series reveals an overall beneficial impact of deployed dropsondes, contributing to a reduction of the short-range forecast error. Dropsonde observations near tropical cyclones during SHOUT and Reconnaissance (SR) show a larger impact per observation than NAWDEX (NAW) dropsondes deployed in midlatitude systems. In combination with the large number of SR dropsondes, this results in about $60 \%$ of the total impact of all additional observations. For SR dropsonde observations that focus on Karl and Matthew, large beneficial impacts are found around the time when the storms transition into the midlatitudes, which is temporally in agreement with the identified episodes of large forecast error reduction.

The recently introduced new dropsonde quality control appears to increase the impact of dropsonde observations significantly and seems to successfully mitigate issues with the assimilation of dropsondes in the core and eyewall region encountered in previous studies (e.g., Harnisch and Weissmann 2010). Nevertheless, the horizontal drift of assimilated dropsondes is not yet taken into account explicitly, leaving room for further improvement.

Per observation, the impact of NAWDEX dropsondes was smaller than that of SR dropsondes near tropical cyclones, but still 4-5 times larger than the mean impact of operational radiosondes. In total, NAWDEX dropsondes contributed about $8 \%$ of the total impact of all extra observations. It should be noted that NAWDEX dropsondes were focusing on the observation of physical processes rather than sensitive regions. Additionally launched Canadian radiosondes exhibit a comparable impact per observation to NAWDEX dropsondes and constitute around $20 \%$ of the total impact. The impact of additional European radiosondes was comparable to operational radiosondes.

In summary, the study reveals a beneficial impact of dropsonde and additional radiosonde observations in the current ECMWF system. Episodes of tropical cyclones interacting with the midlatitude waveguide appear to be particularly sensitive to additional observations. Midlatitude dropsonde observations over the Atlantic and additional Canadian radiosondes exhibit a smaller impact than dropsondes near tropical cyclones, but still an impact that is considerably larger than that of operational radiosondes. Future research will further investigate situations of increased impact in order to identify physical processes causing increased error reduction.

Acknowledgments. The research leading to these results was carried out in the Hans-Ertel Centre for Weather Research (Weissmann et al. 2014; Simmer et al. 2016) and was funded by the German Research 
Foundation (DFG), as part of the Collaborative Research Center SFB/TRR 165 "Waves to Weather" Project A3. The authors gratefully acknowledge the NAWDEX team members for their efforts in mission planning, flight coordination and data collection, as well as the NAWDEX and W2W community for valuable input and fruitful discussions. The authors thank the German Science Foundation (DFG) for supporting the HALO contribution to the NAWDEX campaign within the priority program SPP1294 HALO. Moreover, we would like to thank the SHOUT team for collaboration and access to the observational information collected by Global Hawk and Reconnaissance aircraft. We are particularly grateful to the ECMWF for data access, allocation of computational resources and technical assistance. Special thanks are due to Massimo Bonavita, Cristina Lupu and Carla Cardinali for continued support, valuable suggestions, and constructive comments throughout this study. Furthermore, we would like to thank George Craig for providing new impetus during several discussions. Finally, we are grateful to the reviewers for their suggestions that helped to improve the manuscript.

\section{REFERENCES}

Aberson, S. D., 2003: Targeted observations to improve operational tropical cyclone track forecast guidance. Mon. Wea. Rev., 131, 1613-1628, https://doi.org/10.1175//2550.1.

Amerault, C., K. Sashegyi, P. Pauley, and J. Doyle, 2013: Quantifying observation impact for a limited area atmospheric forecast model. Data Assimilation for Atmospheric, Oceanic and Hydrologic Applications, S. K. Park and L. Xu, Eds., Vol. II, Springer, 125-145.

Baker, N. L., and R. Daley, 2000: Observation and background adjoint sensitivity in the adaptive observation-targeting problem. Quart. J. Roy. Meteor. Soc., 126, 1431-1454, https:// doi.org/10.1002/qj.49712656511.

Baker, W. E., and Coauthors, 2014: Lidar-measured wind profiles: The missing link in the global observing system. Bull. Amer. Meteor. Soc., 95, 543-564, https://doi.org/10.1175/BAMSD-12-00164.1.

Bauer, P., A. Thorpe, and G. Brunet, 2015: The quiet revolution of numerical weather prediction. Nature, 525, 47-55, https:// doi.org/10.1038/nature14956.

Bonavita, M., L. Isaksen, and E. Hólm, 2012: On the use of EDA background error variances in the ECMWF 4D-Var. Quart. J. Roy. Meteor. Soc., 138, 1540-1559, https://doi.org/10.1002/ qj.1899.

— , and Coauthors, 2017: On the initialization of tropical cyclones. ECMWF Tech. Memo. 810, ECMWF, 41 pp., https:// doi.org/10.21957/insgrw8u6.

Cardinali, C., 2009: Monitoring the observation impact on the short-range forecast. Quart. J. Roy. Meteor. Soc., 135, 239-250, https://doi.org/10.1002/qj.366.

Chou, K. H., C. C. Wu, P. H. Lin, S. D. Aberson, M. Weissmann, F. Harnisch, and T. Nakazawa, 2011: The impact of dropwindsonde observations on typhoon track forecasts in DOTSTAR and T-PARC. Mon. Wea. Rev., 139, 1728-1743, https://doi.org/ 10.1175/2010MWR3582.1.

Christophersen, H., A. Aksoy, J. Dunion, and S. Aberson, 2018: Composite impact of Global Hawk unmanned aircraft dropwindsondes on tropical cyclone analyses and forecasts. Mon. Wea. Rev., 146, 2297-2314, https://doi.org/10.1175/MWRD-17-0304.1.

Dunion, J. P., G. A. Wick, P. G. Black, and J. Walker, 2018: Sensing hazards with operational unmanned technology: 2015-2016 Campaign Summary, Final Report. NOAA Tech. Memo. OAR-UAS-001, 49 pp., https://doi.org/10.7289/V5/ TM-OAR-UAS-001.

ECMWF, 2019: Implementation of IFS Cycle 43r1. ECMWF, accessed 20 August 2019, https://confluence.ecmwf.int/display/ FCST/Implementation + of + IFS + Cycle $+43 r 1$.

Evans, C., and Coauthors, 2017: The extratropical transition of tropical cyclones. Part I: Cyclone evolution and direct impacts. Mon. Wea. Rev., 145, 4317-4344, https://doi.org/10.1175/ MWR-D-17-0027.1.

Gelaro, R., and Y. Zhu, 2009: Examination of observation impacts derived from observing system experiments (OSEs) and adjoint models. Tellus, 61A, 179-193, https://doi.org/10.1111/ j.1600-0870.2008.00388.x.

Grams, C. M., and H. M. Archambault, 2016: The key role of diabatic outflow in amplifying the midlatitude flow: A representative case study of weather systems surrounding western North Pacific extratropical transition. Mon. Wea. Rev., 144, 3847-3869, https://doi.org/10.1175/MWR-D-15-0419.1.

— S. C. Jones, C. A. Davis, P. A. Harr, and M. Weissmann, 2013: The impact of Typhoon Jangmi (2008) on the midlatitude flow. Part I: Upper-level ridgebuilding and modification of the jet. Quart. J. Roy. Meteor. Soc., 139, 2148-2164, https://doi.org/ 10.1002/qj.2091.

Hamill, T. M., F. Yang, C. Cardinali, and S. J. Majumdar, 2013: Impact of targeted winter storm reconnaissance dropwindsonde data on midlatitude numerical weather predictions. Mon. Wea. Rev., 141, 2058-2065, https://doi.org/10.1175/ MWR-D-12-00309.1.

Harnisch, F., and M. Weissmann, 2010: Sensitivity of typhoon forecasts to different subsets of targeted dropsonde observations. Mon. Wea. Rev., 138, 2664-2680, https://doi.org/10.1175/ 2010MWR3309.1.

Isaksen, L., M. Bonavita, R. Buizza, M. Fisher, J. Haseler, M. Leutbecher, and L. Raynaud, 2010: Ensemble of data assimilations at ECMWF. ECMWF Tech. Memo. 636, ECMWF, 48 pp., https://doi.org/10.21957/obke4k60.

Janisková, M., and C. Cardinali, 2016: On the impact of the diabatic component in the Forecast Sensitivity Observation Impact diagnostics. ECMWF Tech. Memo. 786, ECMWF, 20 pp., https://doi.org/10.21957/jfw5fmxox.

Jones, S. C., and Coauthors, 2003: The extratropical transition of tropical cyclones: Forecast challenges, current understanding, and future directions. Wea. Forecasting, 18, 1052-1092, https:// doi.org/10.1175/1520-0434(2003)018<1052:TETOTC >2.0.CO;2.

Keller, J. H., and Coauthors, 2019: The extratropical transition of tropical cyclones. Part II: Interaction with the midlatitude flow, downstream impacts, and implications for predictability. Mon. Wea. Rev., 147, 1077-1106, https://doi.org/10.1175/ MWR-D-17-0329.1.

Kren, A. C., L. Cucurull, and H. Wang, 2018: Impact of UAS Global Hawk dropsonde data on tropical and extratropical cyclone forecasts in 2016. Wea. Forecasting, 33, 1121-1141, https://doi.org/10.1175/WAF-D-18-0029.1. 
Langland, R. H., 1999: The North Pacific Experiment (NORPEX98): Targeted observations for improved North American weather forecasts. Bull. Amer. Meteor. Soc., 80, 1363-1384, https://doi.org/10.1175/1520-0477(1999)080<1363:TNPENT> 2.0.CO;2.

- 2005: Issues in targeted observing. Quart. J. Roy. Meteor. Soc., 131, 3409-3425, https://doi.org/10.1256/qj.05.130.

- and N. L. Baker, 2004: Estimation of observation impact using the NRL atmospheric variational data assimilation adjoint system. Tellus, 56A, 189-201, https://doi.org/10.1111/ j.1600-0870.2004.00056.x.

Majumdar, S. J., 2016: A review of targeted observations. Bull. Amer. Meteor. Soc., 97, 2287-2303, https://doi.org/10.1175/ BAMS-D-14-00259.1.

_ numerical weather prediction: An overview. THORPEX International Programme Office, THORPEX Publication 15, WMO, 45 pp., https://www.wmo.int/pages/prog/arep/wwrp/ new/documents/THORPEX_No_15.pdf.

Malardel, S., N. Wedi, W. Deconinck, M. Diamantakis, C. Kuehnlein, G. Mozdzynski, M. Hamrud, and P. Smolarkiewicz, 2016: A new grid for the IFS. ECMWF Newsletter, No. 146, ECMWF, Reading, United Kingdom, 23-28, https://doi.org/10.21957/ zwdu9u5i.

McNally, A. P., 2002: A note on the occurrence of cloud in meteorologically sensitive areas and the implications for advanced infrared sounders. Quart. J. Roy. Meteor. Soc., 128, 2551-2556, https://doi.org/10.1256/qj.01.206.

Montani, A., A. J. Thorpe, R. Buizza, and P. Undén, 1999: Forecast skill of the ECMWF model using targeted observations during FASTEX. Quart. J. Roy. Meteor. Soc., 125, 3219-3240, https:// doi.org/10.1002/qj.49712556106.

Oertel, A., M. Boettcher, H. Joos, M. Sprenger, H. Konow, M. Hagen, and H. Wernli, 2019: Convective activity in an extratropical cyclone and its warm conveyor belt-A case study combining observations and a convection-permitting model simulation. Quart. J. Roy. Meteor. Soc., 145, 1406-1426, https://doi.org/10.1002/qj.3500.

Peevey, T. R., J. M. English, L. Cucurull, H. Wang, and A. C. Kren, 2018: Improving winter storm forecasts with observing system simulation experiments (OSSEs). Part I: An idealized case study of three U.S. storms. Mon. Wea. Rev., 146, 1341-1366, https://doi.org/10.1175/MWR-D-17-0160.1.

Rabier, F., H. Järvinen, E. Klinker, J.-F. Mahfouf, and A. Simmons, 2000: The ECMWF operational implementation of four-dimensional variational assimilation. I: Experimental results with simplified physics. Quart. J. Roy. Meteor. Soc., 126 , 1143-1170, https://doi.org/10.1002/qj.49712656415.

_ - , and Coauthors, 2008: An update on THORPEX-related research in data assimilation and observing strategies. Nonlinear Processes Geophys., 15, 81-94, https://doi.org/ 10.5194/npg-15-81-2008.

Schäfler, A., and Coauthors, 2018: The North Atlantic Waveguide and Downstream Impact Experiment. Bull. Amer. Meteor. Soc., 99, 1607-1637, https://doi.org/10.1175/BAMS-D17-0003.1.

Simmer, C., and Coauthors, 2016: HErZ: The German Hans-Ertel Centre for Weather Research. Bull. Amer. Meteor. Soc., 97, 1057-1068, https://doi.org/10.1175/BAMS-D-13-00227.1.

Simmons, A. J., and A. Hollingsworth, 2002: Some aspects of the improvement in skill of numerical weather prediction. Quart. J. Roy. Meteor. Soc., 128, 647-677, https://doi.org/10.1256/ 003590002321042135.

Szunyogh, I., Z. Toth, R. Morss, S. J. Majumdar, B. J. Etherton, and C. H. Bishop, 2000: The effect of targeted dropsonde observations during the 1999 Winter Storm Reconnaissance Program. Mon. Wea. Rev., 128, 3520-3537, https://doi.org/ 10.1175/1520-0493(2000)128<3520:TEOTDO > 2.0.CO;2.

— S. J. Majumdar, A. V. Zimin, A. Persson, and Z. Toth, 2002: Propagation of the effect of targeted observations: The 2000 Winter Storm Reconnaissance Program. Mon. Wea. Rev., 130, 1144-1165, https://doi.org/10.1175/1520-0493(2002)130<1144: POTEOT $>2.0 . \mathrm{CO} ; 2$.

Weissmann, M., and Coauthors, 2011: The influence of assimilating dropsonde data on typhoon track and midlatitude forecasts. Mon. Wea. Rev., 139, 908-920, https://doi.org/10.1175/ 2010MWR3377.1.

— R. H. Langland, C. Cardinali, P. M. Pauley, and S. Rahm, 2012: Influence of airborne Doppler wind lidar profiles near Typhoon Sinlaku on ECMWF and NOGAPS forecasts. Quart. J. Roy. Meteor. Soc., 138, 118-130, https://doi.org/10.1002/ qj.896.

_ for Weather Research-A virtual centre at the interface of basic and applied weather and climate research. Meteor. Z., 23, 193-208, https://doi.org/10.1127/0941-2948/2014/0558.

Wick, G. A., J. P. Dunion, and J. Walker, 2018: Sensing hazards with operational unmanned technology: Impact study of Global Hawk unmanned aircraft system observations for hurricane forecasting, Final Report. NOAA Tech. Memo. OAR-UAS-002, 94 pp., https://doi.org/10.7289/V5/TM-OARUAS-002. 